\title{
Children's morphological awareness and reading ability
}

\author{
John R. Kirby • S. Hélène Deacon • Peter N. Bowers • \\ Leah Izenberg • Lesly Wade-Woolley $\cdot$ Rauno Parrila
}

Published online: 25 March 2011

(C) Springer Science+Business Media B.V. 2011

\begin{abstract}
We investigated the effects of morphological awareness on five measures of reading in 103 children from Grades 1 to 3. Morphological awareness was assessed with a word analogy task that included a wide range of morphological transformations. Results indicated that the new measure had satisfactory reliability, and that morphological awareness was a significant predictor of word reading accuracy and speed, pseudoword reading accuracy, text reading speed, and reading comprehension, after controlling the effects of verbal and nonverbal ability and phonological awareness. Morphological awareness also explained variance in reading comprehension after further controlling word reading. We conclude that morphological awareness has important roles in word reading and reading comprehension, and we suggest that it should be included more frequently in assessments and instruction.
\end{abstract}

Keywords Morphological awareness · Reading · Word analogy · Phonological awareness · Reading comprehension

\section{Introduction}

Morphological awareness refers to children's "conscious awareness of the morphemic structure of words and their ability to reflect on and manipulate that

J. R. Kirby $(\bowtie) \cdot$ P. N. Bowers · L. Izenberg · L. Wade-Woolley

Faculty of Education, Queen's University, Kingston, ON K7L 3N6, Canada

e-mail: kirbyj@queensu.ca

S. H. Deacon

Dalhousie University, Halifax, NS, Canada

R. Parrila

University of Alberta, Edmonton, AB, Canada 
structure" (Carlisle, 1995, p. 194). Morphemes are the fundamental building blocks of words within both spoken and written language. Words that contain more than one morpheme can be broken down into these smaller units, providing cues for meaning, spelling, and pronunciation (e.g., Carlisle, 2003). For example, the word payment contains two morphemes, the base pay and the suffix -ment that transforms the verb into a noun. A growing body of research indicates that morphological awareness contributes to reading ability (e.g., Brittain, 1970; Carlisle, 1995; Deacon \& Kirby, 2004; Mahony, Singson, \& Mann, 2000; Nagy, Berninger, \& Abbott, 2006; Nunes \& Bryant, 2006). Our purpose in this paper is to further investigate the nature and extent of the relationship between morphological awareness and children's reading development. We examine this relationship with children from Grades 1 to 3, a younger age range than included in most published studies (for exceptions see Carlisle \& Nomanbhoy, 1993; Carlisle, 1995), because we are interested in the effects of morphological awareness on early literacy skills. We also include a range of reading outcome measures to better gauge the nature of the relationship.

\section{Development of morphological awareness}

Within the domain of morphology, typically a distinction is made between inflectional and derivational morphology. Inflections alter the grammatical function of a word, without changing the word class. For example, the word played is formed when the suffix -ed is added to the base play. The word changes from present to past tense, altering the grammatical function, while the word class, as a verb, remains unchanged. Derivations involve the generation of new words from a base morpheme that differ in meaning and may differ in word class. For example, adding the derivational suffix -ful to the free-standing base play creates the word playful, thereby altering the meaning of the word and changing the word class from a verb to an adjective, whereas adding dis- creates the word display which has a different meaning and can be either a verb or a noun. These morphological transformations in oral language are also encoded in print in English (and in other orthographies). In the word playful, the denotation of the base remains, encoded by the consistent spelling (e.g., play in playful).

Morphological awareness develops with exposure to oral and written English. Evidence of morphological awareness assessed with oral tasks has been found in children as young as four (Berko, 1958). Preschool children show implicit morphological awareness by demonstrating that they understand the ways that morphemes can be combined to express meaning (Carlisle \& Fleming, 2003). Berko's seminal example of four-year-old children's ability to produce the plural wugs for the pseudoword wug demonstrates the ability of preschoolers to inflect words, though her participants were less successful producing other plurals such as tasses, indicating that their morphological development is incomplete. Clark (1982) offered anecdotal evidence of neologisms that preschool children create such as flyable, suggesting the implicit ability of preschool age children to form some (relatively transparent) derived forms. Young elementary-age children can decompose words into component morphemes, before being able to use that information to 
extract meaning or demonstrate awareness of the suffixes that change grammatical roles (Carlisle \& Fleming, 2003; see also Tyler \& Nagy, 1989). Carlisle and Fleming (2003) found that Grade 1 children were able to decompose words with familiar base forms, such as stillness, but were not able to define the words in a way that accounted for the meaning or grammatical role of the suffix. By Grade 3, children were more likely to provide an adequate definition of morphologically complex words on this task, but their difficulties with defining and showing correct use of suffixes continued.

There appears to be a consensus in the literature that children demonstrate morphological awareness as assessed with metalinguistic tasks or in spontaneous productions earlier for inflections than for derivations (Adams, 1990; Carlisle, 2003; Kuo \& Anderson, 2006; see Rabin \& Deacon, 2008 for an exception). However, the majority of studies examining the relationship between morphological awareness and reading with young children have focused typically on inflections while those with older children have targeted derivations (see Carlisle \& Nomanbhoy, 1993, Carlisle, 1995, for exceptions); to sample the full morphological construct, we need to include both inflections and derivations in a measure of morphological awareness. This would allow us to better understand the contribution of morphological awareness as a broad construct to reading development. As an example, the predictive power of a task based solely on inflections might peak early (as suggested by Deacon, Wade-Woolley, \& Kirby 2009), while that from a task that includes derivations might continue to predict reading as children continue their morphological development in this area.

\section{Measurement of morphological awareness}

There are various methods employed to assess morphological awareness that differ across several dimensions (see Deacon, Parrila, \& Kirby, 2008, for a review). Morphology measures can be presented in oral, written, or combined oral and written form. Additionally, morphological awareness tasks can assess judgment, production, or decomposition abilities. Similar results have been found across studies that employ measures with different task characteristics, suggesting that the relationship between morphological awareness and reading is not a result of method (Carlisle, 2003).

In a judgment task, the participant must make a decision, but need not manipulate the structure of a word, or set of words, by applying morphological principles. For example, this is demonstrated when we compare responses to questions such as "Is there a little word in corner that means something like corner?" and "Is there a little word in teacher that means something like teacher?" (Carlisle \& Nomanbhoy, 1993). Production moves beyond recognition and tests the ability to produce words by applying morphological rules. For example, Carlisle (2000) used a production task in which subjects were asked to supply a missing word, given the root morpheme (e.g., "Teach. He was a very good " Correct response: teacher). In contrast, a decomposition task asks the student to identify the correct root of a given derivation or inflection. (e.g., "Runner. How fast can she ?" Correct response: run). 
Both morphological decomposition and production are involved when morphological awareness is tested through word analogy tasks. For example, a participant could be asked to complete patterns such as walk: walked:: shake: (shook) (Nunes, Bryant, \& Bindman, 1997a, b; see also Kemp, 2006). In such a task, the subject must recognize a morphological relationship in the first pair of words (involving decomposition) and then apply this relationship to the third word to generate the appropriate word to solve the analogy (production). The integration of morphological decomposition and production in analogy tasks requires a more explicit level of awareness of morphological patterns than judgment or production tasks (Carlisle, 2003). In addition to the ability to manipulate the morphological structure of words, word analogy likely requires analogical reasoning. Although analogical reasoning adds cognitive complexity to this measure, pre-school children, and even infants are capable of analogical of reasoning (e.g., Chen, Sanchez, \& Campbell, 1997; Goswami, 1995; see Deacon \& Kirby, 2004, for more on this). The Word Analogy test, despite its analogical component, appears to be a suitable morphological awareness measure for young children.

One characteristic relevant to the measurement of morphological awareness concerns the phonological transparency of the relationship between morphologically related words. For example, in the pair help-helpful, the base is pronounced similarly in both, whereas in sign-signal there is a phonological shift. It is more difficult to recognize morphological relationships when there is a phonological shift, and this is particularly true for weaker readers (e.g., Carlisle, 1988; Carlisle, Stone, \& Katz, 2001; Shankweiler et al., 1995). Including phonologically opaque items in measures of morphological awareness, as Nunes et al. (1997a, b) did, helps ensure that participants are processing the morphological structure of the words, not just their phonological structure. Including phonologically transparent items ensures that the task continues to capture the broad construct that is morphological awareness.

The Word Analogy measure of morphological awareness was originally developed by Nunes et al. (1997a, b) and used to predict correct spelling of past tense verb inflections. Deacon and Kirby (2004) showed that it predicted reading ability in Grades 3 to 5. For the present study, we developed a measure which was longer (20 items as opposed to 8) and more broadly-based, addressing a greater range of derivations and inflections.

The relationship between morphological awareness and reading

Building on the substantial existing body of research indicating that morphological awareness contributes to reading competence (see Carlisle, 2003; Carlisle \& Stone, 2005; Deacon \& Kirby, 2004, for reviews), we can identify several areas that continue to require further scrutiny. In our view, the first question is whether morphological awareness makes an independent contribution to reading or whether its effect overlaps entirely with those of other cognitive processes. Previous studies have not been consistent in their use of control measures (see Deacon \& Kirby, 2004; Kuo \& Anderson, 2006). We would argue that the critical variables to include are general cognitive ability and phonological awareness given their established 
roles in predicting reading achievement (e.g., Adams, 1990), We include these in the current study.

A second question of much debate is whether the contribution of morphological awareness to reading ability changes with development. Several studies have shown evidence of an increase in contributions across the elementary school years, a conclusion that is echoed in several literature reviews (e.g., Kuo \& Anderson, 2006). In a cross-sectional study, Singson, Mahony, and Mann (2000) assessed morphological awareness with a sentence completion measure designed to test derivational suffixing ability. Whereas only phonological awareness contributed significantly to reading ability in Grade 3, morphological awareness increased its contribution to reading ability (pseudoword and word reading) in comparison to phonological awareness in Grades 4 through 6, after controlling vocabulary and age. Carlisle (1995) found that, whereas morphological awareness and reading were unrelated in kindergarten, there was a significant relationship in Grade 1. Deacon and Kirby (2004) found that morphological awareness, measured with the Nunes et al. (1997a, b) Sentence Analogy task, predicted pseudoword reading and reading comprehension (but not real word reading) after controlling measures of prior reading ability, verbal and nonverbal intelligence, and phonological awareness; these relationships were stronger in Grades 4 and 5 than they were in Grade 3. However, in separate analyses controlling only intelligence and phonological awareness (omitting the autoregressive factor), morphological awareness contributed to pseudoword reading, real word reading, and reading comprehension at each grade level, and there was no clear increasing trend across grades. Similar findings of equivalent effects across grades came from a cross-sectional study of children in Grades 4, 6, and 8, in which Roman, Kirby, Parrila, Wade-Woolley, and Deacon (2009) found morphological awareness predicted real word and pseudoword reading, after controlling phonological awareness, naming speed, and orthographic knowledge; nonsignificant interactions with age indicated that the relationship between morphological awareness and reading did not change across Grades 4 to 8 . Thus, the results of empirical research to date conflict regarding a possible increase in the effect of morphological awareness on reading. Although it would make intuitive sense for morphological awareness to have more impact as comprehension processes become more important, it may also be that morphological awareness contributes earlier in reading development to word recognition. Clearly more evidence is required on this issue.

A third, and related, question concerns the aspects of reading to which morphological awareness should be most clearly related. The status of morphemes as units of meaning and the role of inflections in forming syntax suggests reading comprehension as the most likely beneficiary of morphological awareness (e.g., Carlisle, 2003; Kuo \& Anderson, 2006). Further, it has been argued that morphological awareness may contribute to text comprehension by supporting the interpretation of unknown words (Carlisle, 2000; Nagy et al., 2006). For example, a reader might recognize the word treelet to mean a small tree, based upon knowledge of the base tree and the suffix -let despite lacking previous exposure to the word (Anglin, 1993). However, morphological awareness may also contribute to accurate word reading, both oral and silent, through analysis of multimorphemic words and 
by exclusion of some pronunciations of single morpheme words. For example, recognizing that react has two morphemes allows its meaning to be identified and increases the likelihood of accurate pronunciation (as suggested by Kuo \& Anderson, 2006). Morphological awareness may even contribute to the pronunciation of pseudowords; Deacon and Kirby (2004) suggested that this may occur if there are plausible morphemic units within made-up words (e.g., the -ed in gaked or the -ful in mancingful). Because awareness of morphemes can speed processing in reading (e.g., Elbro \& Arnbak, 1996), morphological awareness may also contribute to word and text reading speed. Roth, Lai, White, and Kirby (2006) found morphological awareness to contribute to pseudoword reading accuracy, real word reading accuracy and speed, and reading comprehension in Grade 3 children, after controlling the effects of intelligence, phonological awareness, naming speed, and orthographic processing. Given the interdependence of reading processes, it would not be surprising if the effects of morphological awareness extend to many aspects of reading, including speed and accuracy of word recognition and reading comprehension, but to our knowledge most studies have included only one or two reading outcome measures. Our inclusion of multiple measures in the same study should permit us to assess the relative contributions of morphological awareness to different aspects of reading in a manner that has not been common in prior research.

Our fourth question is whether morphological awareness makes a contribution to reading comprehension after accounting for the effects of word reading. This question arises because of the expected contributions of morphological awareness to word reading, and the important role of word reading in reading comprehension (Gough \& Tunmer, 1986). Arguments that morphological awareness has its greatest effect on reading comprehension (e.g., Carlisle, 2003; Kuo \& Anderson, 2006) imply that the relationship between morphological awareness and reading comprehension should withstand controls for word reading. To our knowledge, this prediction has never been tested.

The present study

The goal of this study was to investigate the nature and extent of the relationship between morphological awareness and children's reading development. We wanted to assess the ability of a more broadly-based Word Analogy measure of morphological awareness to explain variance in different aspects of reading within a longitudinal design. We sought to do this in a younger sample than most previous studies have used. We aimed to determine (a) if morphological awareness contributes to reading development beyond intelligence and PA, (b) if the link between morphological awareness and reading changes over time, (c) if the relationships between morphological awareness and various reading measures differ, and (d) whether morphological awareness contributes to reading comprehension after accounting for the effect of word reading. Based on previous research, we hypothesized that morphological awareness would (a) contribute to reading development (e.g., Carlisle \& Stone, 2005; Kuo \& Anderson, 2006), (b) increase its level of contribution to each reading outcome measure with each year (e.g., Singson 
et al., 2000), (c) contribute to a broad range of reading measures (e.g., Deacon \& Kirby, 2004; Roth et al., 2006), and (d) make a unique contribution to reading comprehension (e.g., Carlisle, 2003; Kuo \& Anderson, 2006).

\section{Methods}

\section{Participants}

The participants in this study were 103 children (48 males, 55 females) who were followed from kindergarten to Grade 3 as part of a larger study of reading development. The children were first tested in the latter half of kindergarten (mean age $=5$ years, 7 months), then 6 months later in the first half of Grade 1 (mean age $=6$ years, 1 month), then 12 months later in Grade 2 (mean age $=7$ years, 1 month), and 24 months later in Grade 3 (mean age $=8$ years, 1 month); the SD in each case was 3.6 months. The original sample consisted of 214 children in kindergarten, but over the four years of the project this number was reduced by children leaving the regions in which the study took place, by consent letters that were not returned signed, and by student absences for individual measures. We compared the children who remained in the study with those who left before Grade 3 with respect to three kindergarten variables. The children who left were slightly older $(M=67.9$ months $)$ than those who stayed $(M=66.7), t(212)=2.24$, $p<05$, and had obtained slightly higher scores on Raven's Colored Progressive Matrices $(M=18.6)$ than those who stayed $(M=17.1), t(204)=2.37, p<05$, but the groups did not differ on the Peabody Picture Vocabulary Test-Third Edition $(M \mathrm{~s}=86.2$ and 87.2 and for those who remained and not, respectively), $t(205)=23$, ns. The children came from a broad range of schools in Kingston, Ontario and St. Albert, Alberta, representing a range of socioeconomic backgrounds. The criteria for inclusion in the study were informed parental consent and ability to understand the instructions; the latter was assessed informally in kindergarten by judging children's responses to the instructions for the Raven's and Peabody tests. Each year the participants received a battery of cognitive, linguistic, reading, and spelling measures, only some of which are analyzed in this study.

\section{Measures}

A number of measures were given over the course of the project. These are described below and shown by time of administration in Table 1.

\section{Verbal and nonverbal ability}

In Kindergarten, two intelligence measures were administered. Raven's Colored Progressive Matrices (Raven, 1965) was used to measure general nonverbal intellectual ability. Each of the 36 items on the test requires children to identify which of six designs best completes an incomplete pattern. All items were administered to every child. Each correct answer is awarded one point so that scores 
Table 1 Measures administered in each grade

\begin{tabular}{ll}
\hline Grade & Measures administered \\
\hline Kindergarten & Raven's colored progressive matrices \\
& Peabody picture vocabulary test-III \\
Grade 1 & Word blending \\
& Elision \\
& Word analogy \\
Grade 2 & Word analogy \\
Grade 3 & Word analogy \\
& Word attack \\
& Word identification \\
& Word reading speed \\
& Text reading speed \\
& Passage comprehension \\
\end{tabular}

on the complete test range from 0 to 36 . Internal consistencies reported in Raven, Raven, and Court (1998) fall between .65 and .90 for children aged five to eight. The Peabody Picture Vocabulary Test,Third Edition (Dunn \& Dunn, 1997), was employed to measure verbal ability, and requires the child to point to one of four pictures to best represent a word spoken by the examiner. There are 204 items grouped in sets of 12 . Testing was discontinued when the child responded incorrectly on six or more items in a set. From the manual, alpha coefficients range from .93 to .95 for ages four to seven.

\section{Phonological awareness}

In the fall of Grade 1, two phonological awareness tasks were administered, Word Blending and Elision. In the Word Blending task, from the Comprehensive Test of Phonological Processing (CTOPP; Wagner, Torgesen, \& Rashotte, 1999), the examiner pronounced a series of separate sounds and the participant was to combine them into a whole word (e.g., "sh-ē" into "she") for a total of 20 items. Feedback was provided for the practice items and the first three test items only. The test was discontinued if the participant missed three consecutive items. If the participant requested, the examiner was allowed to repeat the word segments once. The score was the number of correct test items. The test manual gives the estimated alpha reliability as .89 for six-year-olds. The Elision task was adapted from that in the CTOPP (Wagner, Torgesen, \& Rashotte, 1999) by adding six test items, to make a total of 29 items, preceded by three practice items. The added items were easier ones, inserted early in the test, to ensure that all children had full opportunity to understand the task and to avoid potential floor effects for some younger children. Items were recorded digitally with Canadian pronunciation onto a laptop computer and presented through separate speakers. Presentation and response recording was controlled by DirectRT (Corporation 2002). In each trial, a spoken word was presented and the child was asked to repeat it. The computer then asked the child to repeat the word into a microphone without a specified syllable or phoneme 
(e.g., "Say cup without the/k/"). Feedback was provided on all practice items and test items 1 through 12 . The examiner discontinued the task after three consecutive incorrect answers, and the score was the total number of correct responses. The CTOPP manual gives the alpha reliability estimate of .92 for 6 -year-olds. The raw scores for Word Blending and Elision were correlated $r=58(p<.001)$. They were transformed into $z$-scores and averaged; the result is henceforward referred to as phonological awareness.

\section{Morphological awareness}

Morphological awareness was assessed in the fall of Grades 1, 2, and 3 with the Word Analogy task. The participant was asked to provide a missing word based upon a pattern from a set of words (e.g., run: ran:: walk: (walked)). The experimenter said "I am going to ask you to figure out some missing words. If I say push and then I say pushed; then I say jump, so then I should say ...?”. If the child did not respond correctly (jumped), the experimenter explained how push and pushed were alike, and then how jump and jumped were alike the same way. The same procedure was followed for the other five practice examples. The task consisted of two subtasks, one of ten inflectional and one of ten derivational items, given in a fixed order. Approximately half of the items had no phonological change (e.g., walk-walked) and the remainder had phonological changes (e.g., stoodstand); of the inflection items, six had phonological changes; of the derivation items, five had phonological changes. Items were modeled on those used by Nunes et al. (1997a, b) and Kemp (2006) and are given in the Appendix. No feedback was given for the test items and each of the derivational and inflectional subtasks ended after the participant made four consecutive errors. The child's score was the total number of inflected and derived items correct. The split-half reliability coefficients (with Spearman-Brown correction) for the total scores were .80, .91, and .89 at Grades 1, 2 , and 3 , respectively.

\section{Reading ability}

Five measures of reading were administered in Grade 3. Word Attack (Woodcock, 1998) consists of 45 pseudowords presented to the participant in order of increasing difficulty. The participant was asked to read the pseudowords aloud. The examiner discontinued the test after six consecutive errors. The score was the number of correct responses. The test manual reports the split-half reliability in Grade 3 children to be 91 (Woodcock, 1998).

Word Identification (Woodcock, 1998) has 106 items provided in order of decreasing frequency. The participant is asked to read the words on the page. The test was discontinued after six consecutive errors. The score was the number of correct responses. Woodcock (1998) reported a split-half reliability coefficient of .97 for children in Grade 3.

Word Reading Speed was measured by the Test of Word Reading Efficiency (Torgesen, Wagner, \& Rashotte, 1999). The participant is presented with 104 words of increasing difficulty and asked to read as many out loud as possible in $45 \mathrm{~s}$. 
The score is the number of words read correctly. The manual gives an alternative forms reliability estimate of .95 for 8 -year-olds.

A Text Reading Speed measure was created, using two passages from the Gray Oral Reading Tests (GORT 4; Wiederholt \& Bryant, 2001). We chose the first two passages of Form B, appropriate for beginning readers, and omitted the comprehension questions. Participants were asked to read both stories out loud, beginning with the easier one, without stopping in-between, as fast as they could without making mistakes. The children were provided with words they could not decode within $5 \mathrm{~s}$ and the number of provided words and the number of errors were recorded. The score on the test is the number of words read correctly (i.e., not including those provided) divided by the time it took the child to read both stories, in words per minute. Reliability was estimated by correlating the reading speeds for the two stories separately, $r=76, p<.001$.

In Passage Comprehension (Woodcock, 1998), the participant is presented with a series of up to 68 passages, each with a missing word represented by a blank line. The participant is asked to read each passage silently and indicate what word should go where the blank line is. The examiner discontinued the test after six consecutive errors, and the score for the child was the number of correct responses. Woodcock (1998) reports the split-half reliability to be .92 .

\section{Results}

The descriptive statistics for all measures are shown in Table 2. The means for Raven and PPVT-III are at or slightly above the norms for Kindergarten children, according to the test manuals. The means for Word Attack, Word Identification, Word Reading Speed, and Passage Comprehension are all typical for Grade 3 children, according to their manuals. The means for Word Analogy suggest that the test was more difficult for the children in Grade 1 (2.83 out of 20) than it was in Grade 2(5.90), and, and more difficult in Grade 2 than in Grade 3 (9.83). Measures with skewness and kurtosis values that fell outside of the acceptable range

Table 2 Descriptive statistics

All measures are number of items correct except Text Reading Speed which is in words correct per minute. $N=103$ for all variables

\begin{tabular}{lrr}
\hline Measure & Mean & \multicolumn{1}{c}{ SD } \\
\hline Kindergarten raven & 17.09 & 4.77 \\
Kindergarten PPVT-III & 86.71 & 14.94 \\
Gr 1 phonological awareness & -.07 & .87 \\
Gr 3 Word attack & 22.88 & 10.08 \\
Gr 3 Word identification & 59.09 & 15.45 \\
Gr 3 Word reading speed & 54.85 & 15.07 \\
Gr 3 Text reading speed & 129.89 & 50.75 \\
Gr 3 Passage comprehension & 30.38 & 7.17 \\
Gr1 Word analogy & 2.83 & 2.65 \\
Gr 2 Word analogy & 5.90 & 3.65 \\
Gr 3 Word analogy & 9.83 & 4.21 \\
\hline
\end{tabular}


Table 3 Correlations between variables

\begin{tabular}{lllllllllll}
\hline & 1 & 2 & 3 & 4 & 5 & 6 & 7 & 8 & 9 & 10 \\
\hline 1. K Raven & - & & & & & & & & & \\
2. K PPVT-III & $.42^{* *}$ & - & & & & & & & \\
3. Gr 1 Phon. aware. & $.47^{* *}$ & $.50^{* *}$ & - & & & & & & & \\
4. Gr 3 Word attack & $.45^{* *}$ & $.36^{* *}$ & $.66^{* *}$ & - & & & & & & \\
5. Gr 3 Word ID & $.52^{* *}$ & $.43^{* *}$ & $.68^{* *}$ & $.88^{* *}$ & - & & & & & \\
6. Gr 3 Word read. sp. & $.46^{* *}$ & $.44^{* *}$ & $.61^{* *}$ & $.79^{* *}$ & $.83^{* *}$ & - & & & & \\
7. Gr 3 Text read. sp. & $.41^{* *}$ & $.40^{* *}$ & $.51^{* *}$ & $.67^{* *}$ & $.74^{* *}$ & $.83^{* *}$ & - & & & \\
8. Gr 3 Passage comp. & $.54^{* *}$ & $.62^{* *}$ & $.66^{* *}$ & $.73^{* *}$ & $.78^{* *}$ & $.79^{* *}$ & $.71^{* *}$ & - & & \\
9. Gr 1 Morph. aware. & $.16^{*}$ & .12 & $.24^{* *}$ & $.19^{*}$ & $.20^{*}$ & .04 & .07 & .07 & - & \\
10. Gr 2 Morph. aware. & $.44^{* *}$ & $.53^{* *}$ & $.54^{* *}$ & $.52^{* * *}$ & $.58^{* *}$ & $.51^{* *}$ & $.46^{* *}$ & $.59^{* *}$ & $.23^{* *}$ & - \\
11. Gr 3 Morph. aware. & $.44^{* *}$ & $.58^{* *}$ & $.58^{* *}$ & $.55^{* * *}$ & $.62^{* * *}$ & $.57^{* *}$ & $.60^{* *}$ & $.67^{* *}$ & $.46^{* *}$ & $.66^{* *}$ \\
\hline
\end{tabular}

$* p<.05 ; * * p<.01$

(i.e., statistic/SE $<-3.09$ or $>3.09$ ), were transformed according to the guidelines set out in Tabachnick and Fidell (2007). Specifically, square root transformations were used to bring skewness and kurtosis values within the acceptable range for Word Attack, Word Identification, Word Reading Speed, Passage Comprehension, and Grade 1 morphological awareness. All further analyses were performed with the transformed variables.

Correlations among measures are reported in Table 3. Morphological awareness scores were significantly correlated between grades, the highest (.66) being between grades 2 and 3. Morphological awareness scores in Grades 2 and 3 were significantly correlated with each of the outcome variables and with each of the other predictors (range .44-.62). Grade 1 morphological awareness scores were less related to predictors and outcomes (range .04-.24).

Effect of morphological awareness on reading

Hierarchical regression analyses were conducted to investigate if morphological awareness is a unique predictor of reading after controlling for intelligence and phonological awareness. Three regression analyses were conducted for each of the five reading outcome variables. In each model, the Kindergarten general ability measures (i.e., PPVT and Raven) were entered in the first step. In the second step, phonological awareness (the composite of the Grade 1 Word Blending and Elision tasks) was entered. In the third step the morphological awareness measure from Grades 1, 2, or 3 was entered (thus the three separate analyses for each outcome). This sequence of predictors was selected to control first for verbal and nonverbal intelligence and all the background variables that may have contributed to them, and secondly for phonological awareness, an established predictor of reading (Adams, 1990). Morphological awareness was entered at the third step, to estimate its effect after taking account of intelligence and phonological awareness. The outcome measure in each of the analyses was one of five reading measures, respectively: 
Table 4 Summary of hierarchical regression analyses predicting reading outcomes

\begin{tabular}{|c|c|c|c|c|c|c|c|c|c|c|}
\hline \multirow[t]{2}{*}{$\begin{array}{l}\text { Step, } \\
\text { predictor }\end{array}$} & \multicolumn{2}{|c|}{ Word attack } & \multicolumn{2}{|c|}{$\begin{array}{l}\text { Word } \\
\text { identification }\end{array}$} & \multicolumn{2}{|c|}{$\begin{array}{l}\text { Word reading } \\
\text { speed }\end{array}$} & \multicolumn{2}{|c|}{$\begin{array}{l}\text { Text reading } \\
\text { speed }\end{array}$} & \multicolumn{2}{|c|}{$\begin{array}{l}\text { Passage } \\
\text { comprehension }\end{array}$} \\
\hline & $\beta$ & $\Delta R^{2}$ & $\beta$ & $\Delta R^{2}$ & $\beta$ & $\Delta R^{2}$ & $\beta$ & $\Delta R^{2}$ & $\beta$ & $\Delta R^{2}$ \\
\hline 1. K IQ & & $.22 * * *$ & & $.30 * * *$ & & $.27 * * *$ & & $.28 * * *$ & & $.40^{* * *}$ \\
\hline K Raven & $.34 * *$ & & $.39 * * *$ & & $.27 * *$ & & $.28^{* *}$ & & $.29 * * *$ & \\
\hline K PPVT & $.20^{*}$ & & $.24 *$ & & $.34 * *$ & & $.34 * *$ & & $.45 * * *$ & \\
\hline 2. Gr 1 PA & $.54 * * *$ & $.20 * * *$ & $.52 * * *$ & $.19 * * *$ & $.46 * * *$ & $.15 * * *$ & $.35^{* *}$ & $.08 * * *$ & $.40 * * *$ & $.11^{* * *}$ \\
\hline 3a. Gr $1 \mathrm{MA}$ & .04 & .00 & .05 & .00 & -.10 & .01 & -.04 & .00 & -.04 & .00 \\
\hline 3b. Gr $2 \mathrm{MA}$ & $.23^{*}$ & $.03 *$ & $.26 * *$ & $.04 * *$ & .10 & .01 & $.20^{*}$ & $.03 *$ & $.24 * *$ & $.04 * *$ \\
\hline 3c. Gr 3 MA & $.28^{* *}$ & $.04 * *$ & $.30 * * *$ & $.05 * * *$ & $.23^{*}$ & $.03 *$ & $.40 * * *$ & $.09 * * *$ & $.33 * * *$ & $.06^{* * *}$ \\
\hline
\end{tabular}

$* p<.05 ; * * p<.01 ; * * * p<.001$

Word Attack, Word Identification, Word Reading Speed, Text Reading Speed, and Passage Comprehension.

The results of the regression analyses are shown in Table 4 . The table reports the standardized beta coefficient from the step at which the predictor first entered the model and the variance added at each step. The final three lines of the table show the effects of morphological awareness measured at the three different grade levels.

The verbal and nonverbal measures accounted for 22 to $40 \%$ of the variance in the outcomes; the highest amount was for Passage Comprehension (the task most clearly requiring general cognitive ability), the lowest for Word Attack. Phonological awareness added a further 8 to $20 \%$ of the variance, the highest being for Word Attack (the most phonologically-dependent outcome), the lowest being for Text Reading Speed. Given the age of the children, the low difficulty of the Text Reading Speed passages, and the small effect of phonological awareness on Text Reading Speed, it is clear that speed was due more to factors other than phonological processes; one likely candidate is orthographic processing in sight word recognition. Thus, the first two steps accounted for between 36 and $51 \%$ of the outcome variance.

The effects of morphological awareness depended upon the grade in which it was assessed. When measured in Grade 1, it made no significant contribution to any of the reading outcomes, effect sizes ranging from 0 to $1 \%$. Measured at Grade 2, effect sizes ranged from 1 to $4 \%$, with all but one, that for Word Reading Speed, being statistically significant. When measured in Grade 3, each of the morphological awareness effects was significant and effect sizes ranged from 3 to $9 \%$. The two largest effects were for the two comprehension measures: Text Reading Speed and Passage Comprehension; the morphological awareness beta coefficients for these two variables were comparable in magnitude to those of phonological awareness, entered a step earlier.

Effect of morphological awareness specifically on reading comprehension

Two further hierarchical regression analyses were performed, to examine whether morphological awareness affected reading comprehension above and beyond the 
Table 5 Summary of hierarchical regression analyses predicting text reading speed and reading comprehension controlling word reading

\begin{tabular}{|c|c|c|c|c|c|}
\hline \multicolumn{6}{|l|}{ Outcome variable } \\
\hline \multicolumn{3}{|l|}{ Text reading speed } & \multicolumn{3}{|l|}{ Passage comprehension } \\
\hline Step, predictor & $\beta$ & $\Delta R^{2}$ & Step, predictor & $\beta$ & $\Delta R^{2}$ \\
\hline 1. K IQ & & $.28 * * *$ & 1. K IQ & & $.40 * * *$ \\
\hline K Raven & $.28 * * *$ & & K Raven & $.29^{* *}$ & \\
\hline K PPVT & $.34 * * *$ & & K PPVT & $.45^{* *}$ & \\
\hline 2. Gr 1 PA & $.35 * * *$ & $.08 * * *$ & 2. Gr $1 \mathrm{PA}$ & $.40 * * *$ & $.11 * * *$ \\
\hline 3. Gr 3 Word reading speed & $.83 * * *$ & $.40 * * *$ & 3. Gr 3 Word identification & $.61 * * *$ & $.19 * * *$ \\
\hline 4. Gr 3 MA & $.22 * *$ & $.03 * *$ & 4. Gr 3 MA & $.17^{* *}$ & $.02 *$ \\
\hline
\end{tabular}

$* p<.05 ; * * p<.01 ; * * * p<.001$

effects on word reading. As in the previous analyses, verbal and nonverbal ability were entered in step one and phonological awareness was entered in step two. For the analysis predicting Passage Comprehension, Word Identification was entered at step three, because both measure accuracy rather than speed; for the analysis predicting Text Reading Speed, Word Reading Speed was entered at this step, because each measures speed in addition to accuracy. In the fourth step of both models, the morphological awareness scores from Grades 3 were entered; we chose to use only Grade 3 scores because of the results of the previous analyses. Results for these two analyses are shown in Table 5. In each analysis, the word reading measure accounts for a considerable amount of variance, even after the mental ability and phonological awareness measures are entered in the models; the first three steps account for $70-76 \%$ of the variance. Morphological awareness accounts for a further small but significant amount of variance in each analysis, 2-3\%, indicating that it contributes to text reading above and beyond its effects on word reading.

Supplementary analyses of word analogy task

During the review of this paper, an anonymous reviewer raised an important question about the nature of the Word Analogy test items. Nunes et al. (1997a, b) had embedded phonological changes in 7 of their 8 items, so that the sound change made in the first part of the analogy (e.g., the change from walk to walked) was not identical to the change made in the remainder of the item (changing shake to shook). They did so to ensure that the task could not be performed in a purely phonological manner, without making use of morphology. We used a broader range of items, to ensure a comprehensive assessment of children's morphological awareness. Of the 20 items used in the present study, 12 had different phonological changes in the two word pairs (like those in Nunes et al.'s task). The other 8 items had the same phonological changes in the first and second word pairs (e.g., doll: dolls:: sneaker: (sneakers)), but 2 of these 8 had an additional phonological change in the first word pairs (i.e., anger: angry:: sun: (sunny) and science: scientist:: art: (artist)). 
Table 6 Descriptive statistics for word analogy subscores

\begin{tabular}{lllll}
\hline Grade & \multicolumn{2}{l}{$M$ items } & & \multicolumn{2}{l}{ PM items } \\
\cline { 2 - 3 } & $M$ & SD & & $M$ \\
\hline 1 & .58 & 1.03 & 2.26 & SD \\
2 & 1.78 & 2.25 & 4.01 & 2.07 \\
3 & 4.36 & 2.75 & 5.47 & 2.08 \\
\hline
\end{tabular}

$\mathrm{M}$ items are those that can only be solved by a morphological manipulation; $P M$ items are those that could be solved by either a phonological or a morphological manipulation. Maximum possible score is 12 for $M$ items, 8 for PM items

To examine the possible effects of these item differences, we formed two Word Analogy subscores: one the sum of the 12 items that require a morphological manipulation (i.e., inflection items 1, 3, 4, 5, 6, 7, 8, and 10; derivation items 5, 6, 8, and 9; we term these the $\mathrm{M}$ items) and one the sum of the 8 items that could be performed through a phonological or morphological manipulation (i.e., inflection items 2 and 9; derivation items 1, 2, 3, 4, 7, and 10; we term these the PM items); item classification is indicated in the Appendix. Means and standard deviations for these scores in Grades 1, 2, and 3 are shown in Table 6. The M items were clearly more difficult than the PM items, reflected by significant paired samples $t$ tests comparing the proportion correct at each grade, $t \mathrm{~s}(102)=8.54,10.59$, and 4.55 at Grades 1, 2, and 3 respectively, all $p \mathrm{~s}<.001$. The correlations between the two subscores were $.40, .50$, and .51 in Grades 1,2 , and 3, respectively (all $p$ s $<.001$ ). The correlations between the PM subscore and the phonological awareness composite score that was used in the regression analyses were $.29(p<.01), .46$ $(p<.001)$, and $.48(p<.001)$ in Grades 1,2 , and 3, respectively; those between the $\mathrm{M}$ subscore and phonological awareness were $.31(p<.01), .36(p<.001)$, and .50 $(p<.001)$ in Grades 1, 2, and 3, respectively. These correlations show that the two subscores are moderately related to each other at each grade level, and that they are related to phonological awareness similarly at each grade level, though this relationship is weaker in Grade 1.

We then repeated the analyses shown in Table 4 using the M or PM subscores instead of the total Word Analogy score. The results for the final steps of these analyses are shown in Table 7, with the results from Table 4 for comparison. For the Grade 1 Word Analogy total score there had been no significant effects, and the few significant effects for the M or PM subscores were weak or negative. In Grade 2 , there had been significant effects for the total score on four of the five outcomes, and this was also the case for the subscores. The PM subscore had three significant effects $(p<.05)$ and one marginal effect $(p<.10)$, whereas the M subscore had two significant effects and one marginal effect. In Grade 3 there had been significant effects for all five outcomes, as there were for the subscores. The PM subscore had significant effects on all five outcomes, and the $\mathrm{M}$ subscore had significant effects on four, plus one marginal effect. Although the effects are in several instances weaker for the subscores than the total score, there is no clear pattern of one 
Table 7 Summary of final step of hierarchical regression models predicting reading outcomes from morphological awareness subscores

\begin{tabular}{|c|c|c|c|c|c|c|c|c|c|c|}
\hline \multirow[t]{2}{*}{ Step, predictor } & \multicolumn{2}{|c|}{ Word attack } & \multicolumn{2}{|c|}{$\begin{array}{l}\text { Word } \\
\text { identification }\end{array}$} & \multicolumn{2}{|l|}{$\begin{array}{l}\text { Word } \\
\text { reading } \\
\text { speed }\end{array}$} & \multicolumn{2}{|c|}{$\begin{array}{l}\text { Text reading } \\
\text { speed }\end{array}$} & \multicolumn{2}{|c|}{$\begin{array}{l}\text { Passage } \\
\text { comprehension }\end{array}$} \\
\hline & $\beta$ & $\Delta R^{2}$ & $\beta$ & $\Delta R^{2}$ & $\beta$ & $\Delta R^{2}$ & $\beta$ & $\Delta R^{2}$ & $\beta$ & $\Delta R^{2}$ \\
\hline \multicolumn{11}{|l|}{ Grade 1} \\
\hline 3a. MA (Total) & .04 & .00 & .05 & .00 & -.10 & .01 & -.04 & .00 & -.04 & .00 \\
\hline 3ai. MA (PM) & .06 & .00 & .03 & .00 & $-.15 \dagger$ & $.02 \dagger$ & -.13 & .01 & -.02 & .00 \\
\hline 3aii. MA (M) & $-.15 \dagger$ & $.02 \dagger$ & -.07 & .00 & $-.18 *$ & $.03 *$ & -.08 & .00 & .00 & .00 \\
\hline \multicolumn{11}{|l|}{ Grade 2} \\
\hline 3b. MA (Total) & $.23 *$ & $.03 *$ & $.26^{* *}$ & $.04 * *$ & .10 & .01 & $.20 *$ & $.03 *$ & $.24 * *$ & $.04 * *$ \\
\hline 3bi. MA (PM) & $.20 *$ & $.03 *$ & $.15 \dagger$ & $.02 \dagger$ & .10 & .01 & $.22 *$ & $.04 *$ & $.19 *$ & $.03 *$ \\
\hline 3bii. MA (M) & $.16 \dagger$ & $.02 \dagger$ & $.24 * *$ & $.04 * *$ & .08 & .00 & .12 & .01 & $.18^{*}$ & $.02 *$ \\
\hline \multicolumn{11}{|l|}{ Grade 3} \\
\hline 3c. MA (Total) & $.28 * *$ & $.04 * *$ & $.30 * * *$ & $.05 * * *$ & $.23 *$ & $.03 *$ & $.40 * * *$ & $.09 * * *$ & $.33 * * *$ & $.06 * * *$ \\
\hline 3ci. MA (PM) & $.21 *$ & $.03 *$ & $.26^{* *}$ & $.04 * *$ & $.21 *$ & $.03^{*}$ & $.23 *$ & $.03 *$ & $.32 * * *$ & $.07 * * *$ \\
\hline 3cii. MA (M) & $.29 * *$ & $.05 * *$ & $.27 * *$ & $.04 * *$ & $.16 \dagger$ & $.02 \dagger$ & $.33 * *$ & $.07 * *$ & $.29 * *$ & $.05 * *$ \\
\hline
\end{tabular}

$\mathrm{M}$ items are those that can only be solved by a morphological manipulation; $P M$ items are those that could be solved by either a phonological or a morphological manipulation

$\dagger p<.10, * p<.05 ; * * p<.01 ; * * * p<.001$

Table 8 Summary of final step of hierarchical regression models predicting reading comprehension from morphological awareness subscores after controlling word reading

\begin{tabular}{|c|c|c|c|c|c|}
\hline \multicolumn{6}{|l|}{ Outcome variable } \\
\hline \multicolumn{3}{|c|}{ Text reading speed } & \multicolumn{3}{|c|}{ Passage comprehension } \\
\hline Step, predictor & $\beta$ & $\Delta R^{2}$ & Step, predictor & $\beta$ & $\Delta R^{2}$ \\
\hline Grade 3 & & & Grade 3 & & \\
\hline 4. MA (Total) & $.22 * *$ & $.03 * *$ & 4. MA (Total) & $.17 * *$ & $.02 *$ \\
\hline 4i. MA (PM) & .08 & .00 & 4i. MA (PM) & $.17^{*}$ & $.02 *$ \\
\hline 4ii. MA (M) & $.22 * *$ & $.03 * *$ & 4ii. MA (M) & $.13^{\dagger}$ & $.01^{\dagger}$ \\
\hline
\end{tabular}

$\mathrm{M}$ items are those that can only be solved by a morphological manipulation; $P M$ items are those that could be solved by either a phonological or a morphological manipulation

$\dagger p<.10, * p<.05 ; * * p<.01 ; * * * p<.001$

subscore having more significant effects than the other. There appears to be a good deal of similarity in the results from the total score and the subscores.

We then repeated the analyses shown in Table 5, predicting Text Reading Speed and Passage Comprehension after controlling word reading, using the Word Analogy subscores in the final step. The results for the final steps are shown in Table 8. For Text Reading Speed, the M subscore had a significant effect, of the same magnitude as the total score. For Passage Comprehension, the PM subscore 
had a significant effect, again of the same magnitude as the total score. We will return to the question of what these subscores represent in the Discussion.

\section{Discussion}

The purpose of this study was to investigate the nature and extent of the relationship between morphological awareness and children's reading development in Grades 1 to 3 . We focused on a particular measure of morphological awareness, an extended Word Analogy task similar to those which had been used successfully in previous studies (Deacon \& Kirby, 2004; Kemp, 2006; Nunes et al., 1997a, b). We measured morphological awareness at three points in time (Grades 1, 2, and 3) to examine how it developed and to determine if performance at these three times was differentially related to reading outcomes in Grade 3. We measured a range of reading outcomes, including word reading and comprehension, accuracy and fluency measures, to determine the extent of the effects of morphological awareness on diverse aspects of reading competence. Finally, we tested whether morphological awareness made a unique contribution to reading comprehension after taking into account its effects on word reading.

Role of morphological awareness in reading development

Our primary question in this study concerned the role of morphological awareness, as measured by the Word Analogy task, in reading development. Previous research had led us to expect that morphological awareness would make a small but significant contribution to reading ability after controlling intelligence and phonological awareness (e.g., Carlisle, 2000; Carlisle \& Nomanbhoy, 1993; Mahony et al., 2000; Roman et al., 2009; Roth et al., 2006; Singson et al., 2000). Our second question was whether the relationship between morphological awareness and reading would change over time. Previous research, however, had been inconsistent with regard to this.

The present results show several clear patterns. First, morphological awareness measured in Grade 3 was more powerful in predicting Grade 3 reading ability after accounting for the effects of intelligence and phonological awareness, compared to morphological awareness measured in the other grades. Even though the Grade 1 and Grade 2 morphological awareness scores were correlated significantly with each other and the Grade 3 morphological awareness score, the correlations between Grade 1 morphological awareness and reading were small, and those between Grade 2 morphological awareness and reading were generally smaller than those in Grade 3 (see Table 3). After accounting for intelligence and phonological awareness, the Grade 1 score had no significant effects on any reading score, and the Grade 2 score had significant effects on four reading measures. The Grade 3 score had significant effects upon all five of the reading outcomes, and each was larger than that in Grade 2.

There are several possible interpretations for the finding that Grade 3 scores predicted better than those from Grades 1 and 2, none of which are mutually 
exclusive. One reason would simply be that predictors are more effective when they are measured closer in time to the outcomes; Grade 3 morphological awareness was measured much closer in time to Grade 3 reading than Grade 1 and 2 morphological awareness were. Furthermore, morphological awareness is in a period of growth during the early elementary school years (see Table 1) and the relations between predictors and outcomes are unlikely to be stable when either is undergoing growth (see discussion in Parrila, Aunola, Leskinen, Nurmi, \& Kirby, 2005). It is possible that Grade 1 morphological awareness was related to Grade 1 reading achievement, but that growth in morphological awareness was not consistent across children; this is supported by the lower correlations between morphological awareness in Grade 1 and the later years (see Table 3). It is also possible that parts of the Word Analogy task are too difficult for the children when they are younger. This is supported by the very low performance in the Grade 1 morphological awareness task (see Carlisle \& Nomanbhoy, 1993 for similar findings). Finally, it is possible that the relationship between morphological awareness and reading actually does increase with grade, associated with an increase in reading for meaning. As described in the literature review, Carlisle (1995) and Singson et al. (2000) also found increases in the relationship between morphological awareness and reading with grade, but Roman et al. (2009) did not, and Deacon and Kirby (2004) found mixed results. There is not yet any clear explanation for the different results. One possibility is that the change occurs relatively early, perhaps between kindergarten and Grade 4, and is constant after that; the Singson et al., Carlisle, and Deacon and Kirby studies each included participants younger than Grade 4, whereas Roman et al. had older participants.

The word analogy measure

Performance on the expanded Word Analogy measure increased across grades. Although it is possible that repetition of the same items may have created a practice effect, this seems unlikely over a 12-month interval. The Word Analogy measure performed adequately in Grades 2 and 3, but was too difficult for children in Grade 1. As is suggested by their average score of less than 3 out of 20 items, many Grade 1 children did not understand the task the way it was presented or were unable to perform it. The application of a termination rule in this task, by which each of the inflection and derivation subtasks was ended after four consecutive errors, may have underestimated children's performance. We think this is unlikely, though, because the impression of the testers was that the children whose tests were terminated in this way did not understand the task. In spite of this question, Grade 1 morphological awareness scores were significantly associated with Grade 2 and 3 morphological awareness scores. Although there is clear evidence that much younger children have morphological knowledge (e.g., Berko, 1958), this knowledge is far from complete, as is suggested by the variation Berko found across items, and by Carlisle (1988) and Tyler and Nagy (1989). The decontextualized nature of the Word Analogy task and the requirement of analogical reasoning may be factors in the low performance of the younger children.

Our analyses addressed a concern that performance on some items of the Word Analogy task might be driven by phonological processes alone. Of the 20 items in 
the task, 8 could be solved with either a phonological or a morphological strategy (the PM items). For example, in doll: dolls:: sneaker: (sneakers), a participant could detect the one phoneme $(-s)$ that had been added to doll and add the same phoneme to sneaker to obtain the correct answer. Thus the total score for these items could reflect phonological rather than morphological skills, especially in the earlier grades when average performance was low; this is a potential risk due to the relative ease of the PM items compared to the $\mathrm{M}$ items, those that could only be solved morphologically (see Table 5). In designing the measure, we had not thought that it was likely that participants would adopt a phonological strategy for this task because both the practice and test items had a mixture of the two types, but it is clear that the inclusion of these items poses a potential threat to validity.

To address this concern, we carried out post hoc analyses. These analyses show that the PM items are clearly easier to solve than the $M$ items, especially prior to Grade 3. It is possible therefore that the weaker relations between Word Analogy and the reading outcomes in Grades 1 and 2 are due to the use of a phonological strategy with some of the morphological awareness items. However, we do not think that this conclusion is supported by the results of our additional analyses. First, the PM and M subscores were moderately correlated with each other at each grade level, suggesting at least some overlap in the skills that these items tap. Second, the correlations of each subscore with the composite phonological awareness measure (from Grade 1) are roughly equivalent at each grade level, suggesting that one set of items does not appear to draw more heavily on phonological skills than the other. Third, and perhaps most importantly, the two subscores performed similarly in the re-calculated regression analyses (see Tables 7 and 8). Results for the subscores were often weaker than those for the total score, especially in the analyses controlling word reading (Table 8), but this is likely due to the smaller number of items in the subscores than in the total score. Furthermore, we should recall that the Word Analogy test was reasonably reliable (.80, .91, and .89 in Grades 1, 2, and 3, respectively). While this evidence cannot rule out the possibility that the two groups of items are measuring different constructs, we think that it is consistent with the view that they are measuring the same construct. Certainly, it would be important for future studies to examine the construct validity of this and other measures of morphological awareness (see Deacon, Parrila, \& Kirby, 2008, for a discussion of the range of measures that have been used). The remainder of this paper is based on the working hypothesis that the Word Analogy measure does capture the construct of morphological awareness.

\section{Role of morphological awareness in different measures of reading}

Our third question was whether the effect of morphological awareness varied according to the aspect of reading being measured. The independent effects of morphological awareness on reading at Grade 3 were pervasive and consistent. They were in the 3-9\% range, with the largest being for the two measures that involve comprehension: Text Reading Speed and Passage Comprehension (see Table 4). It should be remembered that these effects were above and beyond those of intelligence and phonological awareness, and that the intelligence measures 
included vocabulary. The magnitude of the effects is modest, but they occur after considerable variance has been accounted for by other predictors. As the correlations show, the effect of morphological awareness would have been far more substantial (21-38\%) if it had been entered first in the models. The effects on word reading are consistent with the view that morphological awareness facilitates word reading accuracy and efficiency. The most plausible mechanism by which it does so is via the recognition of morphemes within the words to be read; processing of larger units (morphemes rather than letters) allows words to be recognized more quickly, and may provide cues to pronunciation (Carlisle \& Stone, 2005). Some may find the effect on pseudoword reading (Word Attack) counterintuitive, because pseudowords have no meaning; nevertheless, we can echo Deacon and Kirby's (2004) points that some of the Word Attack pseudowords have clear morpheme units (e.g., the -ed in gaked) and that many others contain recognizable words (e.g., the hop in hopdalhup). For both word and non-word reading, morphological awareness may help in ruling out particular pronunciations by identifying either the presence or absence of morpheme boundaries; it may also give some children the confidence to attempt reading words that are otherwise intimidating because of length or unfamiliarity.

Morphological awareness and reading comprehension

The morphological awareness effects were stronger for the reading comprehension or text-based tasks, and there were morphological awareness effects on these tasks above and beyond the effects on word reading (see Tables 5,8). There are a number of possible explanations for stronger morphological awareness effects on comprehension tasks. One is that these tasks include many more words, and so the word reading effect is compounded. However, the effect of morphological awareness on the comprehension task performance after accounting for word reading effects suggests that this is not the complete explanation. We would argue that there is an additional role for morphological awareness in these tasks, one specifically to do with building comprehension. Greater morphological awareness should help readers determine more accurately and more efficiently the meanings and syntactic roles (Elbro \& Arnbak, 1996; Nagy et al., 2006) of words that would otherwise be unknown or only understood with capacity-consuming effort. These effects are relatively small, approximately $2-3 \%$, but it should be remembered that they are after the other predictors have accounted for $70 \%$ of the variance in Passage Comprehension and $76 \%$ of the variance in Text Reading Speed. We should note that controlling for both verbal and nonverbal intelligence helps rule out other interpretations, such as the potential role of reasoning ability as a third, spurious variable. Similarly it is unlikely that the effect is due to vocabulary because one of the intelligence measures assessed vocabulary.

\section{Conclusions and future directions}

The present study demonstrates a clear effect of the Word Analogy scores across a range of reading ability measures at the Grade 3 level, consistent with much 
previous research on morphological awareness (e.g., Carlisle, 1995; Deacon \& Kirby, 2004; Nunes, et al., 1997a, b). Questions about the nature of the processes underlying the Word Analogy items suggest that further research is required to validate the construct(s) underlying this and other measures of morphological awareness. Our results also show a unique effect of the Word Analogy scores on reading comprehension beyond its effects on word reading, supporting the arguments of Carlisle (2003) and Kuo and Anderson (2006). These findings suggest both that morphological awareness become a more standard component of early assessment batteries, and that it be the target of instruction (Bowers, Kirby, \& Deacon, 2010; Nunes \& Bryant, 2006). The present results also support the need to include morphological awareness within models of reading development.

\section{Appendix: word analogy items}

See Table 9.

Table 9 Word analogy test items

\begin{tabular}{|c|c|c|c|c|c|}
\hline & & se iter & & & \\
\hline 1 & & pushe & um & imped & PM \\
\hline 2 & & : wal & eacl & teach & PM \\
\hline 3 & & irds:: & se: & & M \\
\hline 4 & & sleep & lou & loudy & $\mathrm{PM}$ \\
\hline 5 & & e: bou & $d:: s$ & skipped & PM \\
\hline 6 & & : beal & $1::$ & funny & M \\
\hline Infl & & & De & & \\
\hline 1 & run: ran:: walk: walked & M & 1 & mess: messy:: fun: funny & $\mathrm{PM}$ \\
\hline 2 & doll: dolls:: sneaker: sneakers & $\mathrm{PM}$ & 2 & paint: painter:: bake: baker & $\mathrm{PM}$ \\
\hline 3 & good: better:: low: lower & M & 3 & anger: angry:: sun: sunny & $\mathrm{PM}$ \\
\hline 4 & jumped: jump:: stood: stand & M & 4 & teach: teacher:: work: worker & PM \\
\hline 5 & push: pushed:: lose: lost & M & 5 & high: height:: deep: depth & M \\
\hline 6 & help: helped:: say: said & M & 6 & decision: decide:: action: act & M \\
\hline 7 & mouse: mice:: child: children & M & 7 & science: scientist:: art: artist & PM \\
\hline 8 & heard: hear:: kept: keep & M & 8 & long: length:: wide: width & M \\
\hline 9 & longer: long:: taller: tall & $\mathrm{PM}$ & 9 & warmth: warm:: strength: strong & M \\
\hline 10 & dog: dogs:: person: people & M & 10 & magic: magician:: music: musician & PM \\
\hline
\end{tabular}

The test administrator orally presented the non-italicized words. The participant was to provide the words in italics

$M$ refers to items that require a morphological manipulation and $P M$ refers to items that can be completed with a phonological and/or morphological manipulation 


\section{References}

Adams, M. J. (1990). Beginning to read: Thinking and learning about print. Cambridge, MA: MIT Press. Anglin, J. M. (1993). Vocabulary development: A morphological analysis. Monographs of the Society for Research in Child Development, 58 (Serial No. 238).

Berko, J. (1958). The child's learning of English morphology. Word, 14, 150-177.

Bowers, P. N., Kirby, J. R., \& Deacon, S. H. (2010). The effects of morphological instruction on literacy skills: A systematic review of the literature. Review of Educational Research, 80, 144-179.

Brittain, M. (1970). Inflectional performance and early reading achievement. Reading Research Quarterly, 6, 34-48.

Carlisle, J. F. (1988). Knowledge of derivational morphology and spelling ability in fourth, sixth, and eighth graders. Applied Psycholinguistics, 9, 247-266.

Carlisle, J. F. (1995). Morphological awareness and early reading achievement. In L. B. Feldman (Ed.), Morphological aspects of language processing (pp. 189-209). Hillsdale, NJ: Erlbaum.

Carlisle, J. F. (2000). Awareness of the structure and meaning of morphologically complex words: Impact on reading. Reading and Writing: An Interdisciplinary Journal, 12, 169-190.

Carlisle, J. F. (2003). Morphology matters in learning to read: A commentary. Reading Psychology, 24, 291-332.

Carlisle, J. F., \& Fleming, J. (2003). Lexical processing of morphologically complex words in the elementary years. Scientific Studies of Reading, 7, 239-254.

Carlisle, J. F., \& Nomanbhoy, D. M. (1993). Phonological and morphological awareness in first graders. Applied Psycholinguistics, 14, 177-195.

Carlisle, J. F., \& Stone, C. A. (2005). Exploring the role of morphemes in word reading. Reading Research Quarterly, 40, 428-449.

Carlisle, J. F., Stone, C. A., \& Katz, L. A. (2001). The effect of phonological transparency on reading derived words. Annals of Dyslexia, 51, 249-274.

Chen, Z., Sanchez, R. P., \& Campbell, T. (1997). From beyond to within their grasp: The rudiments of analogical problem solving in 10- and 13-month-olds. Developmental Psychology, 33, 790-801.

Clark, E. (1982). The young word maker: A case study of innovation in the child's lexicon. In E. Wanner \& L. Gleitman (Eds.), Language acquisition: The state of the art (pp. 390-425). Cambridge, UK: Cambridge University Press.

Deacon, S. H., \& Kirby, J. R. (2004). Morphological awareness: Just "more phonological"? The roles of morphological and phonological awareness in reading development. Applied Psycholinguistics, 25, 223-238.

Deacon, S. H., Parrila, R., \& Kirby, J. R. (2008). A review of the evidence on morphological processing in dyslexics and poor readers: A strength or weakness? In F. Manis, A. Fawcett, G. Reid, \& L. Siegel (Eds.), Sage handbook of dyslexia (pp. 212-237). USA: Sage Publications.

Deacon, S. H., Wade-Woolley, L., \& Kirby, J. R. (2009). Flexibility in young second-language learners: Examining the language specificity of orthographic processing. Journal of Research in Reading, 32, 215-229.

Dunn, L. M., \& Dunn, L. M. (1997). Peabody picture vocabulary test (3rd ed.). Circle Pines, Minnesota: American Guidance Service.

Elbro, C., \& Arnbak, E. (1996). The role of morpheme recognition and morphological awareness in dyslexia. Annals of Dyslexia, 46, 209-240.

Empirisoft Corporation. (2002). DirectRT research software (v2002). New York: Empirisoft.

Goswami, U. (1995). Transitive relational mappings in 3- and 4-year-olds: The analogy of Goldilocks and the Three Bears. Child Development, 66, 877-892.

Gough, P. B., \& Tunmer, W. E. (1986). Decoding, reading, and reading disability. Remedial and Special Education, 7, 6-10.

Kemp, N. (2006). Children's spelling of base, inflected, and derived words: Links with morphological awareness. Reading and Writing: An Interdisciplinary Journal, 19, 737-765.

Kuo, L., \& Anderson, R. C. (2006). Morphological awareness and learning to read: A cross-language perspective. Educational Psychologist, 41, 161-180.

Mahony, D., Singson, M., \& Mann, V. (2000). Reading ability and sensitivity to morphological relations. Reading and Writing: An Interdisciplinary Journal, 12, 191-218. 
Nagy, W., Berninger, V. W., \& Abbott, R. D. (2006). Contributions of morphology beyond phonology to literacy outcomes of upper elementary and middle-school students. Journal of Educational Psychology, 98, 134-147.

Nunes, T., \& Bryant, P. (Eds.). (2006). Improving literacy by teaching morphemes. London: Routledge.

Nunes, T., Bryant, P., \& Bindman, M. (1997a). Children's understanding of the connection between grammar and spelling. In B. Blachman (Ed.), Foundations of reading acquisition and dyslexia: Implications for early intervention (pp. 219-240). Mahwah, NJ: Lawrence Erlbaum Associates.

Nunes, T., Bryant, P., \& Bindman, M. (1997b). Morphological spelling strategies: Developmental stages and processes. Developmental Psychology, 33, 637-649.

Parrila, R. K., Aunola, K., Leskinen, E., Nurmi, J.-E., \& Kirby, J. R. (2005). Development of individual differences in reading: Results from longitudinal studies in English and Finnish. Journal of Educational Psychology, 97, 299-319.

Rabin, J., \& Deacon, H. (2008). The representation of morphologically complex words in the developing lexicon. Journal of Child Language, 35, 1-13.

Raven, J. C. (1965). Coloured progressive matrices test. London: Lewis.

Raven, J., Raven, J. C., \& Court, J. H. (1998). Manual for raven's progressive matrices and vocabulary scales. Oxford, England: Psychologists Press.

Roman, A. A., Kirby, J. R., Parrila, R. K., Wade-Woolley, L., \& Deacon, S. H. (2009). Toward a comprehensive view of the skills involved in word reading in Grades 4, 6, and 8. Journal of Experimental Child Psychology, 102, 96-113.

Roth, L., Lai, S., White, B., \& Kirby, J. R. (2006). Orthographic and morphological processing as predictors of reading achievement. Poster presented at the annual meeting of the Society for the Scientific Study of Reading, Vancouver, BC.

Shankweiler, D., Crain, S., Katz, L., Fowler, A. E., Liberman, A. E., Brady, S. A., et al. (1995). Cognitive profiles of reading-disabled children: Comparison of language skills in phonology, morphology, and syntax. Psychological Science, 6, 149-156.

Singson, M., Mahony, D., \& Mann, V. (2000). The relationship between reading ability and morphological skills: Evidence from derivational suffixes. Reading and Writing: An Interdisciplinary Journal, 12, 219-253.

Tabachnick, B. C., \& Fidell, L. S. (2007). Using multivariate statistics (4th ed.). Needham Heights, MA: Allyn \& Bacon.

Torgesen, J. K., Wagner, R. W., \& Rashotte, C. A. (1999). Test of word reading efficiency (TOWRE). Austin, TX: Pro-Ed.

Tyler, A., \& Nagy, W. (1989). The acquisition of English derivational morphology. Journal of Memory and Language, 28, 649-667.

Wagner, R. K., Torgesen, J. K., \& Rashotte, C. A. (1999). Comprehensive test of phonological processing. Austin, TX: PRO-ED Inc.

Wiederholt, J. K., \& Bryant, B. R. (2001). GORT 4-gray oral reading tests. Austin, TX: PRO-ED, Inc. Woodcock, R. (1998). Woodcock reading mastery tests-revised. Circle Pines, MN: American Guidance Service. 